\title{
XXXVII. Description of an apparatus for making carbonated hydrogen gas from pit coal, for the purpose of lighting factories therewith
}

\section{Mr. Samuel Clegg}

To cite this article: Mr. Samuel Clegg (1809) XXXVII. Description of an apparatus for making carbonated hydrogen gas from pit coal, for the purpose of lighting factories therewith , Philosophical Magazine Series 1, 33:131, 217-220, DOI: 10.1080/14786440908562853

To link to this article: http://dx.doi.org/10.1080/14786440908562853

Published online: 18 May 2009.

Submit your article to this journal $\pi$

山 Article views: 2

View related articles 
plig, in its whole length, is nine inches, and has a hole made in its broad part $\mathrm{H}$, through which the nval iron ring $B$ passes easily, and on which the plug can move back wards and forwards, when the ring is hung upon the hook of the lower pulley block of the lifting iackle. CCCC represent the four legs or frame-work of thic quadrangle, D a five-fold tachle, with blucks ten inches in drameier; $\mathrm{E}$ a roller seven inches in diancter, turned by two long iron levers $b \mathrm{~b}$; the handle $I$ is used as a safegriard, and to assist to regulate the power of the levers. In fig. 1, the plug $A$ is shown fixed in the stont $K$, ready to draw it out of the ground, by means of the liing rarkle.

N. B. I he hunder legs of the quadrangle are made to close in between the fure legs, for the convenience of carriage.

XXXVII. Description of an Apparatus for making Carbonated Hydrogen Gas from Pit Coal, for the Purpose of lighling lactories therewith. By Mr. Samuel CLEGG, of hanchester*

WEAir SIR,

HeN your son was in Manchester, he called to see my nepher's, Samuel Clegg's, improved gas lights, and was desurous tw have a plan of his method, which my nephew promised to him, and J undertook to get it conveyed to you. I hive, accordingly, taken the opportunity of sending to the Society of Arts, \&cc., a plan and explanation of his apparatus.

He lighted a large factory in Yorkshire some years ago upon this principle, and has since lighted some buildings in this neighbourhood, and I believe he is the first person who succeeded in rendering these lights free from the offensive sinell which generally accompanies them. My nephew served an apprenticeship to Messrs. Boulton and Watt, of Brmingham, in the steam-engine business, in which he is

* From Transactions of the Society fer the Encouragement of Aris, Manufucaure, and Commerse, for 1808. The silver medal of the Society was voted to the author. 
now engaged here on his own account, and has made covsiderable improvements in their construction.

1 remain, dear sir, your most obedient servant,

Manchester, May 18, 1806.

Ashworth Clegg.

To C. Taylor, M.D. Sec.

SIR,

Your esteemed favour I have received, and, according to your request, have sent you a fuller explanation of the gazometer and lamp, accompanied with further drawings.

A gazometer, containing seven hundred cubical feet af gas, weighs about twenty bundred weight, and costs about two pounds ten shillings the hundred weight.

The whole of an apparatus complete, capable of supporting forty lamps for four hours, each lamp affording light equal to ten candles of eight in the pound, will cost about two hundred and fifty pounds. Each lamp consumes six cubical feet of gas per hour. I am happy to find that the Society have honoured my communications with their attention, and I remain, with great respect,

Sir, your most obedient servant,

S. ClegG.

Manchester, Aug. 12, 1808.

To C. Taylor, M.D. Sec.

Reference to $M r$. S. Clegg's improved Apparatus for extracting Carbonated Hydrogen Gas from Pit Coal. See Plate V. Figs. 1, 2, 3, 4, 5, and 6 .

In fig. 1, $A$ shows the cast iron retort, into which are put the coals intended to be decomposed by means of a fire underneath it, the heat of which surrounds every part of it, excepting the mouth or part by which the coals are introduced. The lid or iron plate $B$, which covers the mouth of the retort, is ground on air tight, and fastened by means of a screw in the centre; $C$ is a shield or saddle of cast iron, to preserve the retort from being injured by the intensity of the fire underneath it, and to cause it to be heated more uniformly, $D D D$ represents the cast iron pipe which con- 
veys all the volatile products of the coal to the refrigeratory of cast iron $E$, in which the tar, \&c., extracted from the coal is depnsited, and from whence they can be pumped out by means of the copper pipe $F . \quad G$ is the pipe which conveys the gas to the top of the cylindrical vessel or receiver $H$; this receiver is air tight at the top, and consequemily the gas displaces the water in the vessel $H$, to a level with the small holes, where the gas is suffered to escape and rise through the water of the well $I$, into the large gazometer $K$. The use of the vessel $\boldsymbol{H}$ is pointed out as follows, viz. If the pipe $G$ reached all through the water, without passing into the vessel $H$, the gas would not be rendered pure or washed; and if part of the pipe did not rise above the water, the water would have free communication with the tar, besides exposing the retort $A$ to a very great pressure, so as to endunger its bursting when red hot. This vessel or receiver $\boldsymbol{H}$, in a large apparatus, is about eighteen inches diameter, and two feet long; the quantity of gas, therefore, which it contains, is sufficient to fill the pipes and retort when cool, and prevents the pipe $G$ trom acting as a syphon, and exposes the gas to the water without endangering the retort.

When the operation begins, the upper part of the cylindrical gazometer $K$, fig. 1, made of wrought irnn plates, is sunk down nearly to a level with the top of the circular well $I$, and is consequently nearly filled with water, but it rises gradually as the gas enters it and displaces the water; the two weights $L L$ suspended over pulley, by chains keep it steady and prevent its turning round, otherwise the lower stays $M$ of the gazometer would come into contact with the vessel $H$. There are two sets of these stays, one shown at $M$, and the other at $N$.

There is also an iron pipe $O$ made fast in the centre of the gazometer by means of the stays, which slides over the upright pipe $P$, by which contrivance the gazometer is kept firm and steady, when out of the well; it likewise prevents the gas from getting into the cast iron pipe $P$, and the copper pipe $R$, any where but through small boles made in the pipe $O$ at $S$ at the top of the gazometer, where the gas is perfectly transparent and fit for use. 
The pure gas enters the tube $O$ at the small holes'made in its top at $S$, and passes on through the tubes $P$ and $R$ to the lamps, where it is consumed and burnt.

The seams of the gazometer are luted to make them air tight, and the whole well painted inside and out, to preserve it from rust.

Fig. 2 shows a horizontal section of the lower hoop of the gazometer $K$ at the part $M$, with its stays or arms, and the manner in which the iron pipe $C$, before described at fig. 1, sliding on the tube $P$, passes through the ring in the centre of the hoop; a horizontal section of the receiver $H$ appears therein.

Fig. 5 shows a section of one of the gas lamps; the space between the outer tube $T$ and the inner tube $V$, is to be filled with gas supplied by the pipe $R$, shown in fig. 1, where a stop cock is inserted for adjusting the flame, which gas passes through a number of small holes made in the outer edge of a circular plate shown at fig. 6 , which unites the tubes $T$ and $V$ at their tops. $V$ is the inner tube which conveys the atmospheric air into the centre of the flame; the upper part of this tube is made conical, or widening outwards, to join a circular plate with holes in it, a horizontal view of which is shown at fig. $6 . W$ is a button, which can be placed at a small distance above the mouth of the lamp, and its use is to convey, in an expanded manner, all the air which rises through this tube to the inner surface of the flame, which assists the combustion very much; this button may be set at any convenient distance above the tubes of the lamp, as it slides in the cross bars $X X$, by which it is supported in the inner tube.

A current of air also passes between the glass tube or chimney and the outer tube $T$, through holes made in the bottom of the glass-holder, as in Argand's lamps; this surrounds the flame, and completes its combustion, as explained by the view, fig. 3, and section, fig. 4 , which have a glass upon each. ZZZZ, figs. 3, 4, 5, and 6, show the tube through which the lamp is supplied with gas from the pipe $R$, fig. 1 . 